\title{
Seasonal variation of clinical characteristics and prognostic of adult patients admitted to an intensive care unit
}

\author{
(iD) Glaucia Galvão' \\ (D) Ana Luiza Mezzaroba ${ }^{1}$ \\ (iD) Fernanda Morakami² \\ (iD) Meriele Capeletti ${ }^{1}$ \\ (iD) Olavo Franco Filho ${ }^{3}$ \\ (iD) Marcos Tanita ${ }^{4}$ \\ (iD) Tiago Feronato ${ }^{5}$ \\ (iD) Barbara Charneski ${ }^{5}$ \\ (iD) Lucienne Cardoso ${ }^{3}$ \\ (iD Larissa Andrade \\ (iD) Cintia Grion ${ }^{3}$
}

\begin{abstract}
1. Médico intensivista, Mestre, Universidade Estadual de Londrina, PR, Brasil 2. Fisioterapeuta intensivista, Mestre Universidade Estadual de Londrina, PR, Brasil 3. Professor do Departamento de Clínica Médica, Universidade Estadual de Londrina, PR, Brasil 4. Médico intensivista, Doutor, Universidade Estadual de Londrina, PR, Brasil 5. Aluno de graduação em Medicina, Universidade Federal do Paraná, Curitiba, PR, Brasil 6. Professor do Departamento de Estatística, Universidade Estadual de Londrina, PR, Brasil
\end{abstract}

http://dx.doi.org/10.1590/1806-9282.65.11.1374

\section{SUMMARY}

OBJECTIVE: To evaluate seasonal variations of clinical characteristics, therapeutic resource use, and outcomes of critically ill patients admitted to an intensive care unit.

METHODS: A retrospective cohort study conducted from January 2011 to December 2016 in adult patients admitted to the intensive care unit (ICU) of a University Hospital. Data were collected on the type of admission, APACHE II, SOFA, and TISS 28 scores at ICU admission. Length of hospital stay and vital status at hospital discharge were recorded. A significance level of $5 \%$ was adopted.

RESULTS: During the study period, 3.711 patients were analyzed. Patients had a median age of 60.0 years (interquartile range $=45.0-73.0$ ), and 59\% were men. The independent risk factors associated with increased hospital mortality rate were age, chronic disease, seasonality, diagnostic category, need for mechanical ventilation and vasoactive drugs, presence of acute kidney injury, and sepsis at admission.

CONCLUSIONS: It was possible to observe variations of the clinical characteristics and prognosis of patients; summer months presented a higher proportion of clinical and emergency surgery patients, with higher mortality rates. Sepsis at ICU admission did not show seasonal behavior. A seasonal pattern was found for mortality rate.

KEYWORDS: Critical care. Clinical evolution. Severity of illness index. Seasons.

\section{INTRODUCTION}

The concept of grouping patients by severity criteria to improve care and achieve better prognoses is well established in the literature ${ }^{1}$. Intensive care units (ICU) were created to provide specific care to critical patients and rely on a multidisciplinary, specialized, and skilled team and special equipment and technologies ${ }^{2}$. 
There is evidence demonstrating the growing need for more intensive care beds in relation to the number of hospital beds. In the United States, over a period of five years, there was an increase two-times greater of the number of ICU beds in comparison to the number of hospital beds, with a consequent increased cost of the care of critical patients ${ }^{3}$.

In this moment of a growing need for specialized intensive care beds and limited healthcare resources, it is necessary to improve the decision-making process to screen and prioritize the admission of patients into intensive therapy ${ }^{4}$. Early admission of critical patients to an ICU bed is beneficial and capable of reducing mortality; therefore, the knowledge of the clinical profile and the use of therapeutic interventions, as well as their seasonal variations, can help understand and plan the allocation of specialized ICU beds ${ }^{5.6}$.

The objective of this study is to describe seasonal variations of clinical standards, use of resources and outcomes of hospitalized adult patients admitted to the ICU.

\section{METHODS}

The present study was submitted to and approved by the local Research Ethics Committee, and the need to obtain free informed consent forms was waived by decision 1.557.487; CAAE: 56182816.4.0000.5231, report date: May 23, 2016.

A retrospective cohort study carried out from January 2011 to December 2016 in the intensive care unit (ICU) for adult patients of the University Hospital of the State University of Londrina. The adult ICU of the Hospital has 20 beds and is a general ICU for clinical and surgical patients. Within the same institution, there is another ICU specialized in the treatment of severely burned patients, but those beds were not included in this analysis.

We used a convenience sampling of all adult patients admitted to the ICU consecutively during the study period. We included patients with ICU stay time greater than or equal to 24 hours. We excluded patients younger than 18 years old and with ICU readmissions during the period of hospitalization.

The data collected for all ICU admissions were: age, sex, date of admission into hospital and the ICU, type of admission, area of origin, diagnosis for ICU admission, presence of chronic disease. Upon ICU admission, we recorded diagnoses of sepsis and acute renal injury, need for mechanical ventilation, and use of vasoactive drugs. Acute kidney injury was defined as an increase by $50 \%$ of the basal value of serum creatinine ${ }^{7}$, and sepsis was defined as a potentially fatal organic dysfunction caused by an infection ${ }^{8}$. The Acute Physiology and Chronic Health Evaluation (APACHE II), Sequential Organ Failure Assessment (SOFA), and Therapeutic Intervention Scoring System (TISS 28) scores were calculated ${ }^{9}$. Other variables collected were the ICU and hospital stay times. The year was divided into four seasons - summer, fall, winter, and spring, according to the national calendar.

Data collection was performed prospectively and daily by a trained health care professional, so as not to allow losses. The data collection is part of the clinical management of the unit that generates quality indicators. The present study was considered retrospective because it is a retrospective analysis of prospectively collected data. The sources used for data collection were the medical records of the patient and the hospital electronic database. All data used for score calculations were collected as raw data, using the extremes of abnormality during the first 24 hours of ICU stay. The scores were calculated according to the definitions of the respective systems ${ }^{10,11,12}$. Patients were followed-up until the outcome at hospital discharge.

\section{STATISTICAL ANALYSIS}

Continuous variables were expressed as mean and standard deviation (SD) when there was a normal distribution, and as median and interquartile range (IQR) If the distribution was not normal. The categorical variables were expressed as proportions. Descriptive statistics were used to present all relevant variables. The data were presented in graphs and tables. The Kruskal-Wallis test was used for comparison of continuous variables. Categorical variables were compared using the chi-square test of Cochran-Armitage for identifying trends. The variables to predict in-hospital mortality outcomes were presented as unadjusted odds ratios, obtained by logistic regression in enter mode. The stepwise method was used to adjust other predictors of in-hospital mortality in the multivariate analysis, in which variables whose p-value was greater than 0.1 were removed from the model or maintained if $\mathrm{p}<0.05$. Patients in the "elective surgery" and "win- 
ter" groups were considered as the reference categories for logistic regression.

To analyze the effect of seasonality in the main results of the present study, we run a temporal series analysis. In order to do that, we initially studied three monthly time series: total frequency of patients admitted to the ICU (TF), frequency of patients admitted due to sepsis (SF), and frequency of ICU patients who died (DF). With six years of observations, each series includes 72 observations. For better data interpretation, we use frequency rates in relation to the total frequency of patients admitted to the ICU in each month. Thus, the studied series are monthly admission rates due to sepsis ( $\mathrm{SR}=\mathrm{SF} / \mathrm{TF}$ ) and monthly death rate (DR=DF/TF). Then, to transform the series into stationary, we performed a Box-Cox ${ }^{13,14}$ transformation to stabilize the variance. The correlograms present the autocorrelation functions in the time domain, while the periodogram presents the characteristics of the series in the frequency domain. The latter is an important tool to identify periodicities in the data. Based on their estimated frequencies, it is possible to check seasonality and cycles in the series. A Fisher test ${ }^{15}$ was carried out to verify if the seasonal factors were significant.

The level of significance adopted was $5 \%$, and the

FIGURE 1. FLOWCHART OF PATIENTS ADMITTED TO THE INTENSIVE CARE UNIT - ADULTS OF THE UNIVERSITY HOSPITAL, FROM 2011 TO 2016

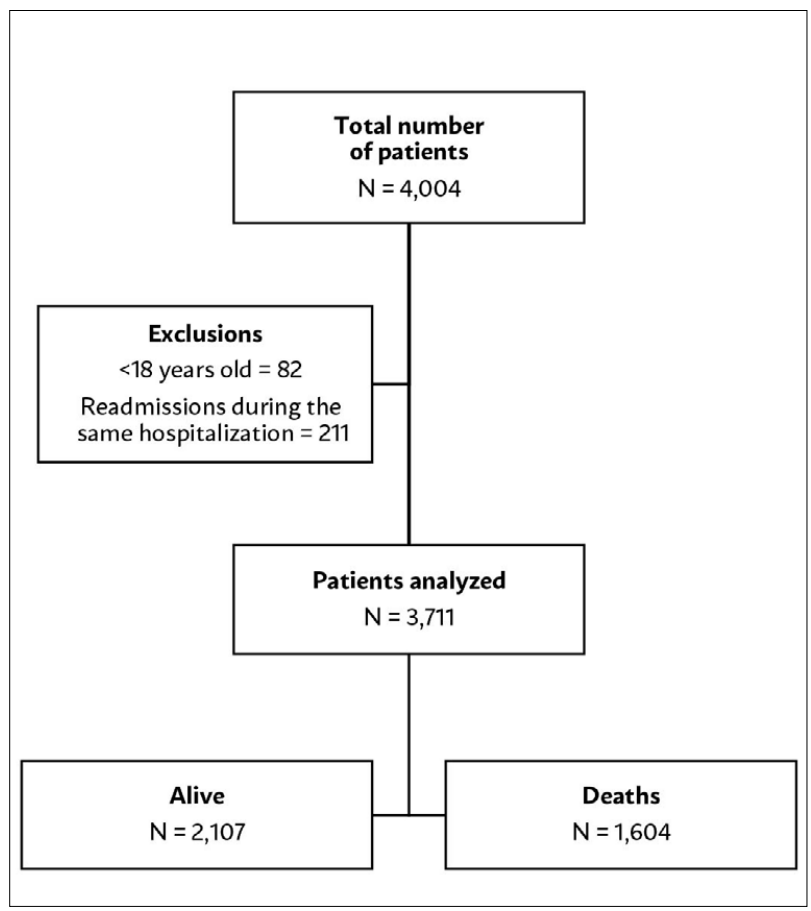

analyses performed used the MedCalc software for Windows, version 18.5 (MedCalc Software, Ostend, Belgium), and the R Project software, 2018 (Austria, Vienna).

\section{RESULTS}

The collection and analysis of data from adult patients admitted to the university hospital ICU from 2011 to 2016 resulted in a total number of 4,004 patients, of which 82 were excluded due to age under 18 years old and 211 due to readmission, leaving 3,711 patients to be analyzed in this study (Figure 1). The annual bed-occupation rates of the unit in the study period ranged from $90.5 \%$ to $96.6 \%$. The median age of patients was 60.0 years $(\mathrm{IQR}=45.0-73.0)$, and $65.8 \%$ were in the range of 31 to 70 years old. In relation to sex, 2,191 (59.0\%) were men. The median ICUstay time was 4.0 days (IQR=1.0 - 11.0), and $58.1 \%$ remained for up to 5 days in the ICU. The hospitalization time presented a median of 16.0 days (IQR $=9.0$ - 30.0), and $66.2 \%$ remained in the hospital for more than 21 days (Table 1 ).

As to the diagnoses for ICU admission, the most frequent were sepsis, in 955 patients $(25.7 \%)$, postoperative of the neurological system in 336 (9.1\%), of

TABLE 1. GENERAL CHARACTERISTICS OF PATIENTS ADMITTED TO THE INTENSIVE CARE UNIT - ADULTS OF THE UNIVERSITY HOSPITAL, FROM 2011 TO 2016

\begin{tabular}{|c|c|}
\hline General Characteristics & $\begin{array}{l}\text { Total } \\
(n=3,711)\end{array}$ \\
\hline $\mathrm{Age}^{*}$ & $60.0(45.0-73.0)$ \\
\hline Malet & $2191(59.0)$ \\
\hline Days of ICU Stay* & $4.0(1.0-10.75)$ \\
\hline Days of Hospital Stay ${ }^{*}$ & $16.0(9.0-30.0)$ \\
\hline Apache $\|^{*}$ & $19.0(13.0-27.0)$ \\
\hline Sofa at admission ${ }^{\star}$ & $6.0(3.0-11.0)$ \\
\hline Tiss-28 at admission* & $26.0(20.0-31.0)$ \\
\hline Mechanical ventilation $†$ & $1,954(52.7)$ \\
\hline SRI at admission $†$ & $1,004(27.1)$ \\
\hline \multicolumn{2}{|c|}{ Diagnostic category at admissiont } \\
\hline Clinical & $1,248(33.6)$ \\
\hline Elective Surgery & $1,438(38.7)$ \\
\hline Emergency Surgery & $1,025(27.6)$ \\
\hline Chronic Disease & $414(11.2)$ \\
\hline Sepsis at Admission† & $955(25.7)$ \\
\hline ICU Mortality† & $1,196(32.2)$ \\
\hline In-Hospital Mortality† & $1,604(43.2)$ \\
\hline
\end{tabular}


FIGURE 2. MONTHLY VARIATION OF THE SEPSIS AND DEATH RATES IN THE INTENSIVE CARE UNIT ADULTS OF THE UNIVERSITY HOSPITAL, FROM 2011 TO 2016

Monthly rate of ICU patients due to sepsis in relation to the total number of ICU patients

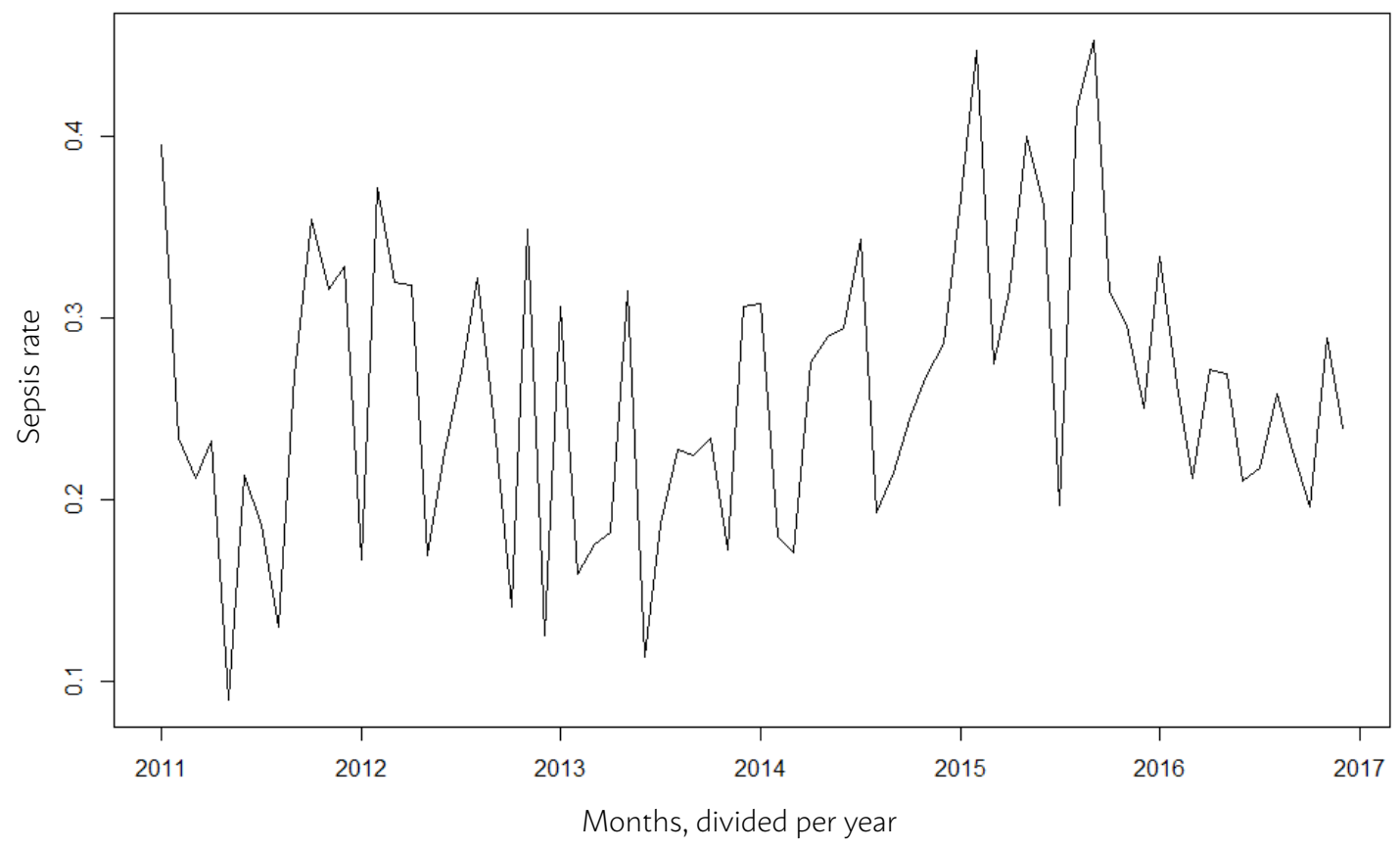

Monthly rate of ICU patients with death outcome in relation to the total number of ICU patients

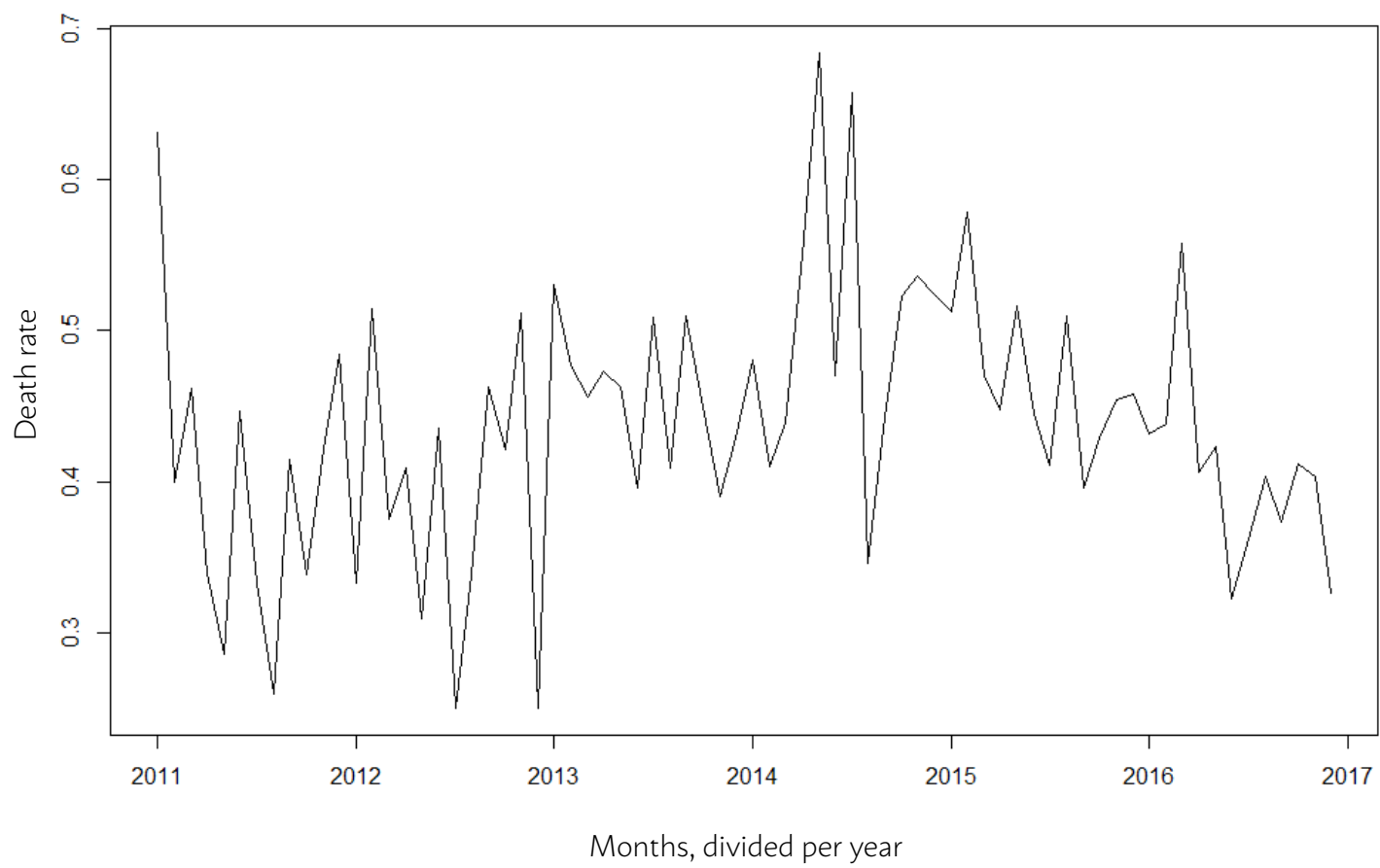


FIGURE 3. GRAPH OF THE TEMPORAL SERIES OF THE SEPSIS RATE AND SEPSIS PERIODOGRAM FOR THE INTENSIVE THERAPY UNIT - ADULTS OF THE UNIVERSITY HOSPITAL, FROM 2011 TO 2016

Series graph with variance stabilized by Box-Cox transformation and without the trend component

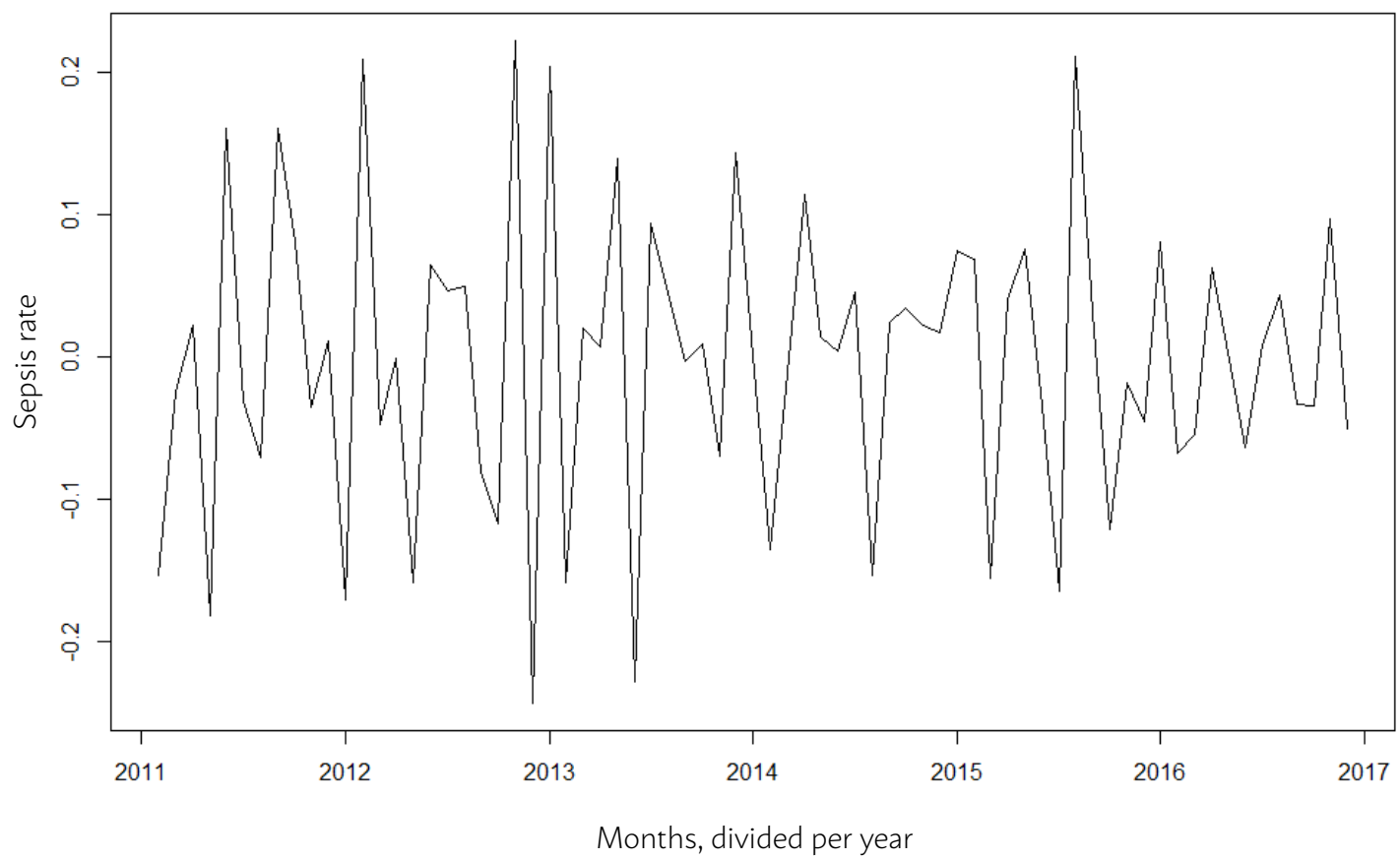

Periodogram for sepsis

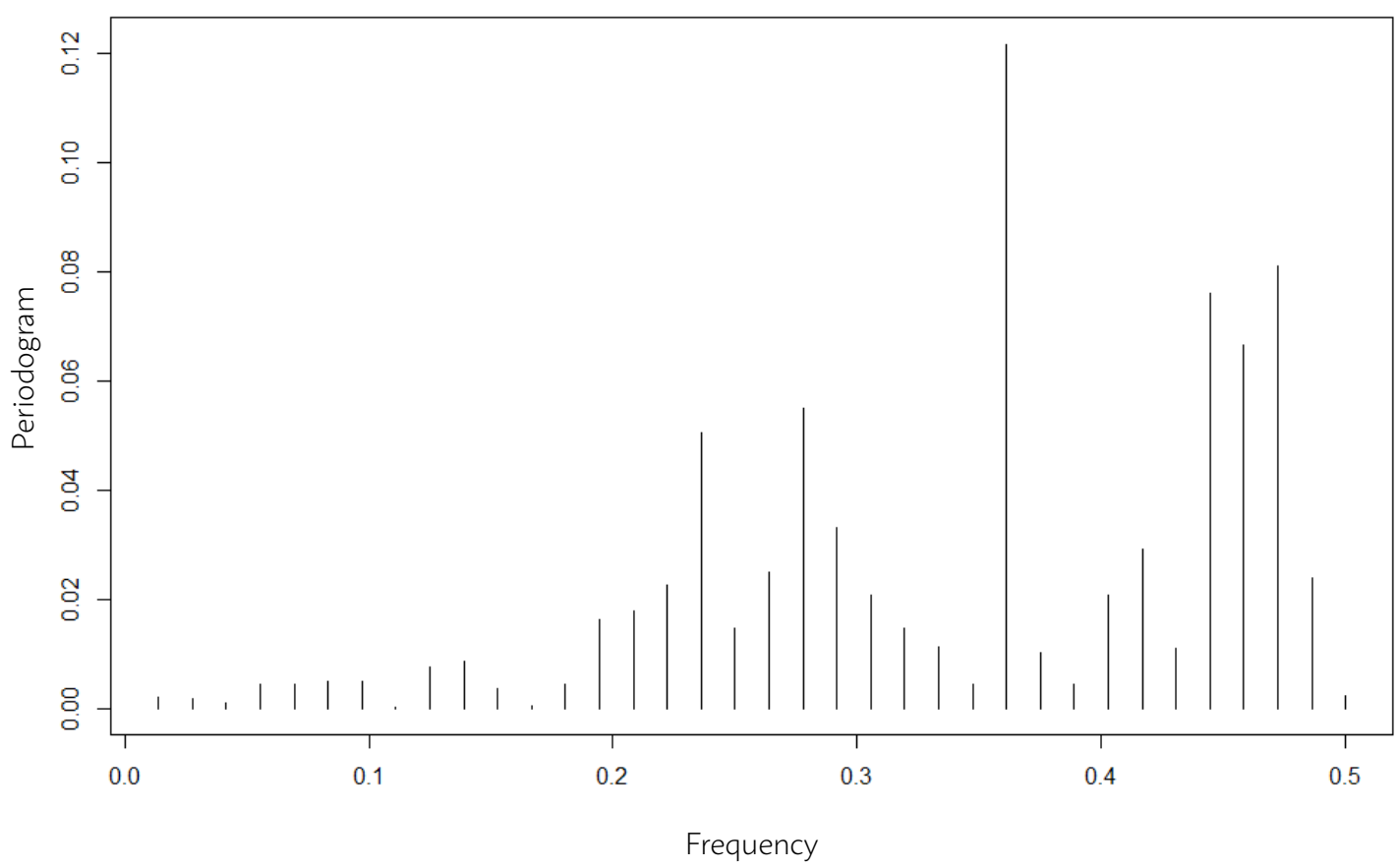


FIGURE 4. GRAPH OF THE TEMPORAL SERIES OF MORTALITY RATE AND DEATH PERIODOGRAM FOR THE INTENSIVE CARE UNIT - ADULTS OF THE UNIVERSITY HOSPITAL, FROM 2011 TO 2016

Series graph with variance stabilized by Box-Cox transformation

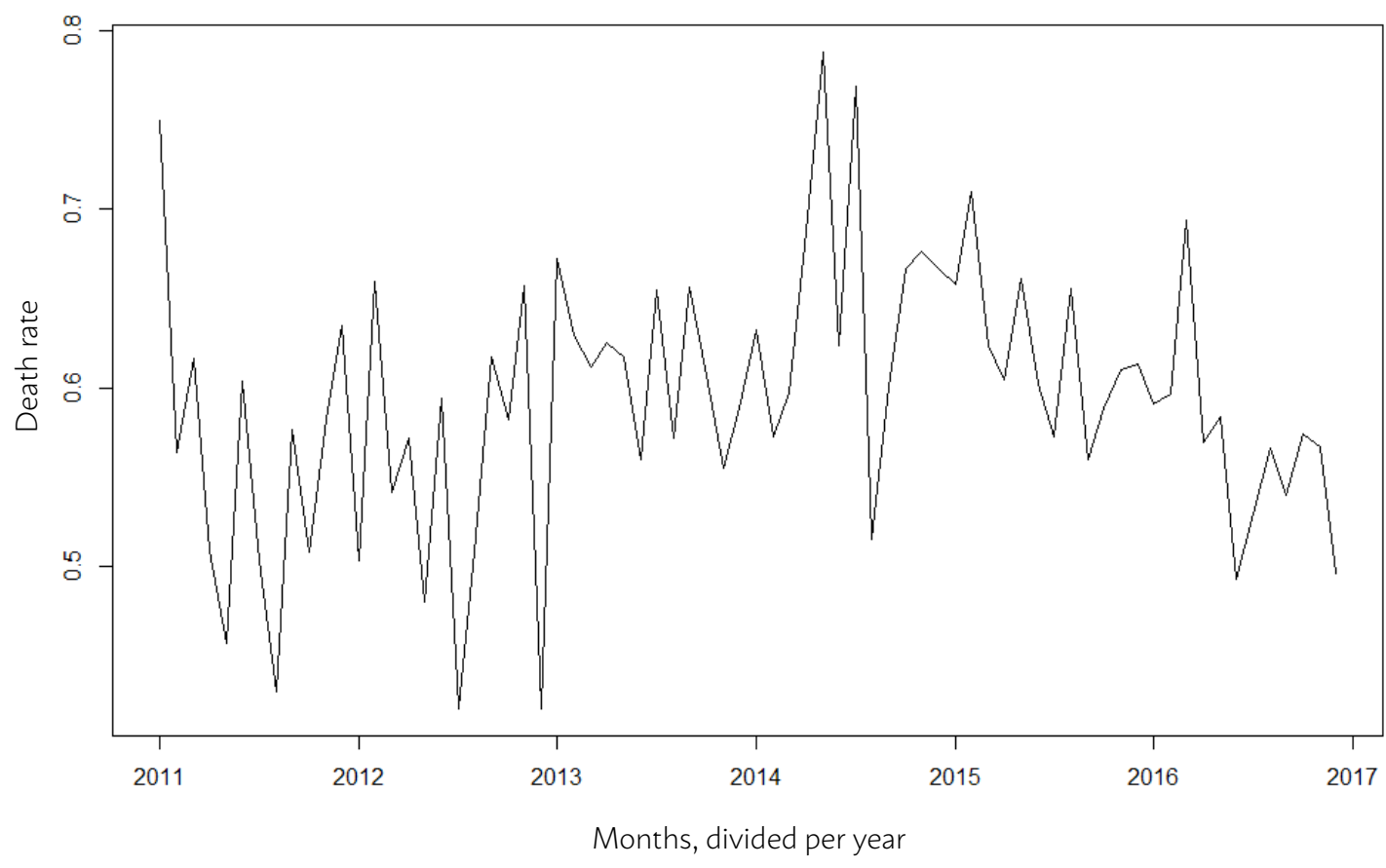

Death Periodogram

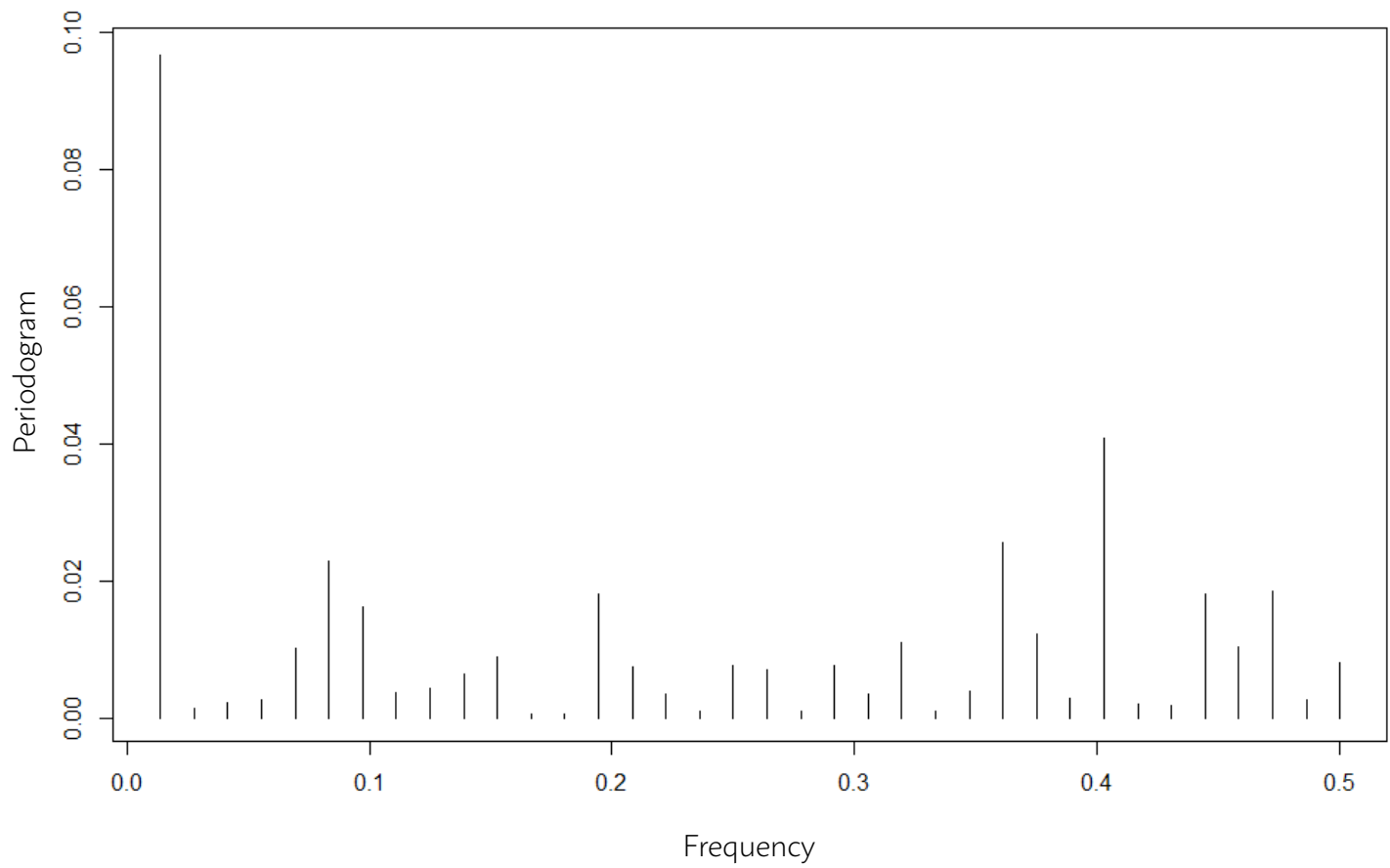


TABLE 2. CHARACTERISTICS OF PATIENTS ADMITTED TO THE INTENSIVE CARE UNIT - ADULTS OF THE UNIVERSITY HOSPITAL, FROM 2011 TO 2016

\begin{tabular}{|c|c|c|c|c|c|}
\hline & $\begin{array}{l}\text { Summer } \\
(n=840)\end{array}$ & $\begin{array}{l}\text { Autumn } \\
(\mathrm{n}=970)\end{array}$ & Winter $(n=1007)$ & Spring $(n=894)$ & $p$ \\
\hline Age (years): median $(\mathrm{IQR})^{\star}$ & $60(45-73.5)$ & $59(45.5-73.5)$ & $60(45-72)$ & $61(46-73.5)$ & 0.525 \\
\hline Male: N (\%)† & $472(56.2)$ & $577(59.5)$ & $610(60.6)$ & $532(59.5)$ & 0.265 \\
\hline Diagnostic Category $†$ & & & & & $<0.001$ \\
\hline Clinical: N (\%) & $320(38.1)$ & $294(30.3)$ & $302(30.0)$ & $338(37.8)$ & \\
\hline Elective Surgery: N (\%) & $296(35.2)$ & $402(41.4)$ & $407(40.4)$ & $349(39.0)$ & \\
\hline Emergency Surgery: N (\%) & $224(26.7)$ & $274(28.2)$ & $298(29.6)$ & $207(23.1)$ & \\
\hline Apache II: Median (IQR) * & $19(13-28.5)$ & $19(12.5-27)$ & $18(12.5-26)$ & $19(13-28.5)$ & 0.250 \\
\hline Sofa: Median (IQR) * & $6(3-11.5)$ & $6(3.5-11)$ & $6(3.5-10.5)$ & $6(3.5-11)$ & 0.111 \\
\hline Tiss-28a: Median (IQR) * & $26(20-31)$ & $25(20.5-31)$ & $26(20.5-31)$ & $26(20.5-31.5)$ & 0.652 \\
\hline Chronic Disease: N (\%)† & $92(10.9)$ & $100(10.3)$ & $102(10.2)$ & $120(13.4)$ & 0.350 \\
\hline Sepsis at ICU admission: $N(\%) \dagger$ & $232(27.6)$ & $238(24.5)$ & $254(25.2)$ & $231(25.8)$ & 0.487 \\
\hline Mechanical ventilation: $\mathrm{N}(\%) \dagger$ & $449(53.4)$ & $505(52.0)$ & $529(52.5)$ & $471(52.7)$ & 0.948 \\
\hline SRI at admission: $\mathrm{N}(\%) \dagger$ & $222(26.4)$ & $253(26.1)$ & $263(26.1)$ & $266(29.7)$ & 0.223 \\
\hline Days in ICU: Median (IQR) * & $4(1-12)$ & $4(1.5-11)$ & $4(1.5-11.5)$ & $4(1-9)$ & 0.053 \\
\hline Days in hospital: Median (IQR) * & $16(10-31.5)$ & $17(9-30)$ & $16(8.5-29.5)$ & $16(8-28)$ & 0.131 \\
\hline ICU Mortality: N (\%) & $306(36.4)$ & $294(30.3)$ & $303(30.1)$ & $293(32.7)$ & 0.013 \\
\hline In-Hospital Mortality: N (\%) & $398(47.4)$ & $415(42.8)$ & $398(39.5)$ & $393(43.9)$ & 0.008 \\
\hline
\end{tabular}

Legend: $I Q R=$ Interquartile range; Apache = Acute Physiology and Chronic Health Evaluation; Sofa = Sequential Organ Failure Assessment at admission; TISS-28a =Therapeutic Intervention Scoring System at admission; ICU = Intensive Care Unit; SRI = Severe renal injury; ${ }^{*}=$ Kruskal-Wallis Test; $\dagger=$ Chi-square test for trends.

TABLE 3. BIVARIATE AND MULTIVARIATE ANALYSIS OF RISK FACTORS FOR IN-HOSPITAL DEATH OF PATIENTS ADMITTED TO THE INTENSIVE CARE UNIT - ADULTS OF THE UNIVERSITY HOSPITAL, FROM 2011 TO 2016

\begin{tabular}{|c|c|c|c|c|c|c|}
\hline & $\begin{array}{l}\text { Unadjusted } \\
\text { odds ratio }\end{array}$ & $\mathrm{Cl} 95 \%$ & $\mathrm{p}$ & $\begin{array}{l}\text { Adjusted } \\
\text { odds ratio }\end{array}$ & $\mathrm{Cl} 95 \%$ & $\mathrm{p}$ \\
\hline Age & 1.01 & $1.01-1.02$ & $<0.001$ & 1.03 & $1.02-1.04$ & $<0.001$ \\
\hline Male & 0.87 & $0.76-1.00$ & 0.050 & & & \\
\hline \multicolumn{7}{|l|}{ Diagnostic category } \\
\hline \multicolumn{7}{|l|}{ Elective surgery (reference) } \\
\hline Emergency surgery & 5.23 & $4.33-6.31$ & $<0.001$ & 2.54 & $2.00-3.23$ & $<0.001$ \\
\hline Clinical & 11.95 & $9.92-14.38$ & $<0.001$ & 3.78 & $2.92-4.89$ & $<0.001$ \\
\hline \multicolumn{7}{|l|}{ Seasonal } \\
\hline \multicolumn{7}{|l|}{ Winter (reference) } \\
\hline Spring & 1.20 & $0.99-1.44$ & 0.050 & & & \\
\hline Summer & 1.37 & $1.14-1.65$ & $<0.001$ & 1.31 & $1.07-1.61$ & 0.008 \\
\hline Autumn & 1.14 & $0.95-1.36$ & 0.141 & & & \\
\hline Apache II & 1.20 & $1.18-1.21$ & $<0.001$ & & & \\
\hline Sofa at admission & 1.40 & $1.37-1.43$ & $<0.001$ & & & \\
\hline Tiss 28 at admission & 1.16 & $1.15-1.18$ & $<0.001$ & & & \\
\hline Chronic disease & 1.31 & $1.14-1.50$ & $<0.001$ & 1.22 & $1.01-1.48$ & 0.034 \\
\hline Sepsis at admission & 6.68 & $5.64-7.90$ & $<0.001$ & 1.45 & $1.15-1.83$ & 0.001 \\
\hline Use of mechanical ventilation & 10.72 & $9.15-12.56$ & $<0.001$ & 4.06 & $3.25-5.08$ & $<0.001$ \\
\hline Use of vasoactive drugs & 7.12 & $6.14-8.26$ & $<0.001$ & 2.74 & $2.26-3.32$ & $<0.001$ \\
\hline SRI at admission & 6.40 & $5.43-7.54$ & $<0.001$ & 2.36 & $1.93-2.98$ & $<0.001$ \\
\hline
\end{tabular}

Legend: Apache = Acute Physiology and Chronic Health Evaluation; Sofa = Sequential Organ Failure Assessment; Tiss 28 = Therapeutic Intervention Scoring System; SRI= Severe real injury; $\mathrm{Cl}=95 \%$ Confidence interval. 
the cardiovascular system in 298 (8.0\%), respiratory system in 247 (6.7\%), and clinical post-cardiac arrest in 135 cases (3.6\%).

We recorded prior diagnoses of chronic diseases in $11.2 \%$ of the patients, and the most frequent were: immunodeficiency $(4.4 \%)$, heart failure (2.1\%), chronic obstructive pulmonary disease (1.8\%), chronic renal insufficiency (1.5\%), and liver cirrhosis (1.4\%). The average APACHE II score was $20.3(\mathrm{SD}=19)$, Sofa average was $6.9(\mathrm{SD}=4.8)$, and Tiss 28 median was $25.8($ IQR $=20.0-31.0)$. Mortality at ICU discharge was $32.2 \%$, and at hospital discharge, $43.2 \%$ (Table 1 ).

After analyzing the variation of illness severity upon ICU admission over the seasons, we found that, although no variation in the severity of patients by age means, presence of chronic disease, or prognostic scores was found, a higher proportion of "Clinical" $(p<0.001)$ and Sepsis diagnosis was identified during the summer months $(\mathrm{p}=0.048)$. These differences in the clinical profile of the patients admitted during the summer resulted in higher hospital mortality rates, compared to the other seasons of the year $(\mathrm{p}=0.007)$ (Table 2).

After studying the risk factors for death at hospital discharge by using the multivariate logistic regression model, seasonality was an independent factor associated with increased in-hospital mortality rates. Furthermore, in the summer, there was an increase of $31 \%$ in the death odds compared to winter months (reference season used in the model). In addition to seasonality, age, diagnostic category, the need for invasive mechanical ventilation, use of vasoactive drugs, presence of chronic disease, diagnosis of acute kidney injury, and sepsis on ICU admission were found to be independent risk factors for death at hospital discharge (Table 3).

To analyze the effect of seasonality in the mortality pattern and its association with the sepsis diagnosis, the temporal series were transformed into a stationary series. Thus, we performed a Box-Cox transformation to stabilize the variance. According to the Wald-Wolfowitz test, it was necessary to subtract the series to remove the trend component. Figure 3 shows the temporal series of monthly sepsis rates. The correlograms with the autocorrelation function in the time domain show that the sepsis rate series does not peak at the beginning and end of each year, during the summer. It is possible to see around three or four peaks of sepsis per year. After analyzing the periodogram for the sepsis rate, we found that the spectral element of order 26 is the one with the highest value. Considering there are 71 observations (we lost one observation after subtraction to remove the trend), this harmony corresponds to a frequency of $71 / 26=3$ months, approximately. Therefore, there is evidence of seasonal behavior of Period 3, i.e., there are peaks of ICU admission due to sepsis every three months, which corroborates what was shown in the series graph.

Similarly, we used the Box-Cox transformation to stabilize the variance of the death rate series. Based on the runs test, the series did not present any trend. Therefore, it was not necessary to do any subtractions in the death rate series. Figure 4 shows the death rate series graph with the Box-Cox transformation and the periodogram. The highest value in the Periodogram is the first spectral element. A Fisher test was performed to check if the seasonality of Period 3 for sepsis and of Period 1 for deaths are significant. According to the test, at a 5\% level of significance, the seasonality for sepsis was not significant, while it was for deaths.

\section{DISCUSSION}

This study presents a detailed description of the clinical characteristics and prognostic indexes of patients admitted to the ICU over a period of six years. It is an intensive care unit with a high occupation rate during the entire study period and a high rate of refusal of admission due to lack of beds. In this context, we found observed an increase of clinical admissions during the summer months, as well as a higher frequency of sepsis diagnosis and the need for invasive mechanical ventilation. Seasonality, age, diagnostic category, the need for invasive mechanical ventilation, use of vasoactive drugs, presence of chronic disease, diagnosis of acute kidney injury, and sepsis on ICU admission were independent risk factors for in-hospital death.

Sepsis is more common in patients with advanced age and chronic disease ${ }^{16}$. It is considered a clinical diagnosis at ICU admission and, by definition, is a condition that presents organic dysfunctions - such as acute kidney injury -, which often require support therapy, such as invasive mechanical ventilation and vasoactive drugs ${ }^{8}$. Due to the association of these variables with the diagnosis of sepsis, we proposed a time-series analysis to confirm the suspected association between seasonal variation, sepsis diagnosis, 
and mortality rate. We confirmed the seasonal pattern of deaths, but not of sepsis diagnosis at the ICU admission.

This variation in the performance of the unit studied is probably due to multiple factors. A recent study of the national registry database for adult patients described a tendency of increased admissions of clinical patients and emergency surgeries over the years and a proportional reduction of elective surgeries $^{17}$. In the institution studied, there is a constant demand for ICU beds that is inhibited. Thus, clinical patients are often treated outside the ICU with the aid of a team specialized in the care of severe patients. During the summer, which coincides with the end of year recesses and holidays, there is a reduction of elective surgeries and increased availability of beds for urgent clinical and surgical patients.

Sepsis was the main clinical diagnosis for patient admission to the ICU. This finding is similar to other data in the literature that demonstrates the impact of sepsis on the occupation rate of intensive care beds ${ }^{18}$. These patients present organic dysfunction at admission with a possibility of worsening during the first hours of care, even after intensive treatment is started, which reflects their severity ${ }^{19}$. A meta-analysis from 1979 to 2015 that evaluated 27 major studies compared the results from the variation of sepsis incidence and found an increase from 288 to 437 cases/100,000 inhabitants/year, and from 148 to 270 cases/100,000 inhabitants/year of cases of severe sepsis, with high rates of in-hospital mortality. In low- and middle-income countries, it is possible that the number of sepsis cases reaches 31.5 million, with 5.3 million deaths/year ${ }^{20}$.

In-hospital mortality rates may be considered high in the present study. It is demonstrated in the literature that high-income countries have lower mortality rates ${ }^{16.21}$ when compared to middle- and low-income countries ${ }^{22.23}$. These differences are due to several factors, among which the structural organization of intensive care units and the ease of access associated with increased availability of intensive care beds in countries with lower mortality rates.

Another Brazilian study, called Orchestra, included 59,693 patients from 78 ICUs and described the association between organizational aspects and mortality rates. The units with a higher level of organization, professionals specialized in intensive care, and use of protocols had the lowest mortality rates $^{24}$. Our study demonstrates that the plan- ning of human resources, equipment, and training should take into account the seasonal changes in the clinical profile of patients admitted. Characteristically, clinical and post-emergency-surgery patients have a higher risk of death; thus, they require more complex treatments and may have longer hospital stays ${ }^{25}$.

The strength of the present study lies in the large number of observations and its long period, allowing detailed descriptions and analysis of annual variations of the outcomes observed. The limitations of the study are due to its single-center design, which limits the extrapolation of results to the populations of institutions with similar characteristics. The study's retrospective nature can also be considered a limitation, but since this is a retrospective analysis of data that were prospectively collected, there were no losses due to incomplete data. To better understand the analysis results of the temporal series, it would be interesting to have a study with a larger number of observations. Although the study involved a long period, the number of observations may not have been sufficient to have the volume of information required to understand the seasonality regarding mortality rates.

\section{CONCLUSION}

In intensive care units with a high occupation rate, it was possible to find a seasonal variation of the clinical profile and prognosis of patients admitted. The summer months had a higher proportion of clinical and emergency-surgery patients, with higher rates of mortality. The suspicion that the sepsis diagnosis at ICU admission had a seasonal 12-month behavior was not confirmed by the time series analysis. We found a seasonal pattern for the mortality rate.

\section{FUNDING}

\section{There was no funding}

This is an original article that was not previously submitted and is not in the process of being submitted to any other journal for publication. All authors approved the final version of the manuscript. This study was approved by the local Research Ethics Committee (Human Research Ethics Committee - State University of Londrina), CAAE: 56182816.4.000.5231. The collection of Informed Consent Forms was waived by the Ethics Committee. 


\section{RESUMO}

OBJETIVO: Analisar variações sazonais dos padrões clínicos, uso de recursos terapêuticos e resultados da internação de pacientes adultos admitidos na unidade de terapia intensiva.

MÉTODOS: Estudo de coorte retrospectivo realizado de janeiro de 2011 a dezembro de 2016 em pacientes adultos na unidade de terapia intensiva (UTI) de Hospital Universitário. Foram coletados dados do tipo de admissão, escores Apache II, Sofa e Tiss 28 da admissão na UTI. O tempo de permanência e o desfecho na saída hospitalar foram registrados. O nível de significância adotado foi de $5 \%$.

RESULTADOS: Foram analisados 3.711 pacientes no período do estudo. Os pacientes apresentaram mediana de idade de 60,0 anos (intervalo interqualítico $=45,0-73,0$ ), sendo 59\% homens. Os fatores independentes associados ao aumento de taxa de mortalidade hospitalar foram idade, doença crônica, sazonalidade, categoria diagnóstica, necessidade de ventilação mecânica e uso de drogas vasoativas, diagnóstico de injúria renal aguda e sepse na admissão. Pela análise de série temporal, a sazonalidade para sepse não foi significativa, enquanto a sazonalidade para óbitos foi significativa.

CONCLUSÕES: Foi possível observar variação do perfil clínico e de prognóstico dos pacientes admitidos, sendo que os meses de verão apresentam maior proporção de pacientes clínicos e cirúrgicos de urgência, com maiores taxas de mortalidade. Sepse na admissão da UTI não apresentou comportamento sazonal. Foi encontrado padrão sazonal para a taxa de mortalidade.

PALAVRAS-CHAVE: Terapia intensiva. Evolução clínica. Índice de gravidade de doença. Sazonalidade.

\section{REFERENCES}

1. Vincent JL, Singer M, Marini JJ, Moreno R, Levy M, Matthay MA et al. Thirty years of critical care medicine. Crit Care. 2010;14(3):311.

2. Keele L, Harris S, Grieve R. Does Transfer to Intensive Care Units Reduce Mortality? A Comparison of an Instrumental Variables Design to Risk Adjustment. Med Care. 2019 Feb 27. doi: 10.1097/MLR.0000000000001093. [Epub ahead of print]

3. Halpern NA, Pastores SM. Critical care medicine in the United States 2000 2005: an analysis of bed numbers, occupancy rates, payer mix, and costs. Crit Care Med. 2010 Jan;38(1):65-71.

4. Nates JL, Nunnally M, Kleinpell R, Blosser S, Goldner J, Birriel B et al. ICU Admission, Discharge, and Triage Guidelines: A Framework to Enhance Clinical Operations, Development of Institutional Policies, and Further Research. Crit Care Med. 2016;44(8):1553-602.

5. Capuzzo M, Moreno RP, Alvisi R. Admission and discharge of critically ill patients. Curr Opin Crit Care. 2010 Oct;16(5):499-504.

6. Cardoso LT, Grion CM, Matsuo T, Anami EH, Kauss IA, Seko L et al. Impact of delayed admission to intensive care units on mortality of critically ill patients: a cohort study. Crit Care. 2011;15(1):R28.

7. Kidney Disease: Improving Global Outcomes (KDIGO). Acute Kidney Injury Work Group. KDIGO Clinical Practice Guideline for Acute Kidney Injury. Kidney Int Suppl. 2012;2(1):1-138.

8. Singer M, Deutschman CS, Seymour CW, Shankar-Hari M, Annane D, Bauer $M$ et al. The Third International Consensus Definitions for Sepsis and Septic Shock (Sepsis-3). JAMA. 2016;315(8):801-10.

9. Vincent JL, Bruzzi de Carvalho F. Severity of illness. Semin Respir Crit Care Med. 2010 Feb;31(1):31-8.

10. Knaus WA, Draper EA, Wagner DP, Zimmerman JE. APACHE II: A severity of disease classification system. Crit Care Med. 1985; 13:18-29.

11. Vincent JL, de Mendonça A, Cantraine F, Moreno R, Takala J, Suter PM et al. Use of the SOFA score to assess the incidence of organ dysfunction-failure in intensive care units: Results of a multicenter; prospective study. Crit Care Med. 1998; 26(11), 1793-1800.

12. Miranda DR, Rijk AP, Schaufeh W. Simplified therapeutic intervention scoring system: the TISS28 iten-results from a multicenter study. Crit Care Med. 1996; 24(1):64-73.

13. Morettin PA, Toloi CMC. Análise de séries temporais. Associação Brasileira de Estatística. São Paulo: Edgard Blücher, 2.ed., 2006. 538p.

14. Box GEP, Cox DR. An analysis of transformations. Journal of the Royal Statistical Society. Series B (Methodological).1964;26(2):211-243.
15. Fisher RA. Tests of significance in harmonic analysis. Proceedings of the Royal Society. Series A. 1929;125:54-59.

16. Herrán-Monge R, Muriel-Bombín A, García-García MM, Merino-García PA, Martínez-Barrios M, Andaluz D et al; GRECIA Network. Epidemiology and Changes in Mortality of Sepsis After the Implementation of Surviving Sepsis Campaign Guidelines. J Intensive Care Med. 2017;1:885066617711882.

17. Zampieri FG, Soares M, Borges LP, Salluh JIF, Ranzani OT. The Epimed Monitor ICU Database ${ }^{\circledast}$ : a cloud-based national registry for adult intensive care unit patients in Brazil. Rev Bras Ter Intensiva. 2017 Oct-Dec;29(4):418-426.

18. Chang DW, Dacosta D, Shapiro MF. Priority Levels in Medical Intensive Care at an Academic Public Hospital. JAMA Intern Med. 2017;177(2):2080-281.

19. Raith EP, Udy AA, Bailey M, McGloughlin S, Maclsaac C, Bellomo R et al; Australian and New Zealand Intensive Care Society (ANZICS) Centre for Outcomes and Resource Evaluation (CORE). Prognostic Accuracy of the SOFA score; SIRS Criteria and qSOFA Score for In-Hospital Mortality Among Adults with Suspected Infection Admitted to the Intensive Care Unit. JAMA. 2017;317(3):290-300.

20. Fleischmann C, Scherag A, Adhikari NK, Hartog CS, Tsaganos T, Schlattmann P et al; International Forum of Acute Care Trialists. Assessment of Global Incidence and Mortality of Hospital-treated Sepsis. Current Estimates and Limitations. Am J Respir Crit Care Med. 2016;193(3):259-72.

21. Paary TTS, Kalaiselvan MS, Renuka MK, Arunkumar AS. Clinical profile and outcome of patients with severe sepsis treated in an intensive care unit in India. Ceylon Medical Journal. 2016;61:181-184.

22. Sales Júnior $A$, David CM, Hatum R, Souza PC, Japiassú A, Pinheiro CT et al; Grupo de Estudo de Sepse do Fundo AMIB. Sepse Brasil: Estudo Epidemiológico da Sepse em Unidades de Terapia Intensiva Brasileiras. Rev Bras Ter Intensiva. 2006;18(1)9-17.

23. Soares M, Bozza FA, Angus DC, Japiassú AM, Viana WN, Costa R et al. Organizational characteristics, outcomes, and resources use in $78 \mathrm{Bra-}$ zilian intensive care units: the ORCHESTRA study. Intensive Care Med. 2015;41:2149-2160.

24. Mclsaac DI, Moloo H, Bryson GL, van Walraven C. The Association of Frailty With Outcomes and Resource Use After Emergency General Surgery: A Population-Based Cohort Study. Anesth Analg. 2017;124(5):1653-1661.

25. García-Gigorro R, Sáez-de la Fuente I, Marín Mateos H, Andrés-Esteban EM, Sanchez-Izquierdo IA, Montejo-González IC. Utility of SOFA and $\triangle$-SOFA scores for predicting outcome in critically ill patients from the emergency department. Eur J Emerg Med. 2018 Dec;25(6):387-393. 